\title{
E-learning and Face to Face Mixed Methodology: Evaluating effectiveness of e-learning and perceived satisfaction for a microeconomic course using the Moodle Platform
}

\author{
Isabel Novo-Corti ${ }^{1,2}$ Laura Varela-Candamioํㅜㄹ ${ }^{1}$ María Ramil-Díaz ${ }^{3}$ \\ ${ }^{1}$ Department of Economic Analysis and Business Administration \\ ${ }^{3}$ Department of Applied Economics II \\ ${ }^{1,3}$ Faculty of Economics and Business, University of A Coruña \\ Campus de Elviña, s/n, 15071, Spain \\ \{isabel.novo.corti; laura.varela.candamio; maria.ramil@udc.es\} \\ ${ }^{2}$ Corresponding author: Isabel Novo-Corti \\ isabel.novo.corti@udc.es \\ Faculty of Economics and Business, University of A Coruña \\ Campus de Elviña, s/n, 15071, Spain \\ Tf. 0034981167000 - Ext. 2445 \\ Fax. 0034981167070
}

\begin{abstract}
The use of Information and Communication Technologies in higher education has proved to be very effective in different educational environments. A less explored area is their application for evaluation on-line, since it is a different process, with specific components. This work describes a methodology that combines the assessment with multiple choice tests through the virtual environment Moodle and the evaluation by using traditional classroom exams. The proposed mixed methodology ELFF (E-Learning and Face to Face) was implemented during the academic year 2010-11 in the subject Microeconomics: Markets and Competition in the European Union of the double degree in Law and in Business Administration and Management, to assess complementary aspects of the knowledge acquired. The obtained results show that it clearly promotes the participation of students, increases their motivation and improves their competence and so, their performance in terms of qualifications.
\end{abstract}

Keywords: E-learning, microeconomics, virtual environments, Moodle, selfperception, motivation

JEL Classification: A23, D00 


\section{Introduction}

The educational value of virtual environments is well known in regard to the transmission of information and interactive participation, either in real time, via video conferences or other alternative systems, or by means of forums, chats, and others ways open to involvement non-simultaneous of participants $[1,2,3]$.

The less explored field of the on-line evaluation presents challenges that, in our opinion, should be undertaken. Its differential aspects with the transmission of information and interaction are many and of a different nature, so the use of virtual tools with this target is more complex. It has specific characteristics, and some advantages and disadvantages compared with the use of the traditional ones [4].

In this paper we present a proposal to evaluate the subject Microeconomics: Markets and Competition, of the second year of the double degree in Law and in Business Administration and Management. This is the E-learning and Face to Face Mixed Methodology (ELFF), which combines traditional assessment by classroom exams with evaluation through virtual environments, by tests with multiple choice answers, that have the advantage of the immediate correction of mistakes, to offer students the opportunity to review their results in order to improve their knowledge [5].

The high level of abstraction of the microeconomic concepts is commonly recognized as one of the major difficulties to learning it. Because of this, in many cases, the students come to know the concepts in isolation, without ever getting to understand which is the role of each piece on the general gear. Thus, they are able to recognize the parts, without comprehending the mechanism of the machine as a whole. It is common that students do not realize of the essence of the relationship between the pieces and the function that each one is playing in the microeconomic model, that is to say, it is usually difficult to them to achieve the conceptual relating knowledge, which is so important to improve understanding of Microeconomics. And one of the main objectives for a teacher is that its pupils get it, to achieve a general understanding of the subject. We think that our proposal may contribute to this.

This work is structured starting with the presentation of the proposal system and the design of the assessment, distinguishing two parts: the face to face and the on-line, and differentiating what is intended to evaluate with each of them, as well as the procedure of qualification. We also present the details of the tests for the on-line evaluation and we describe how we have qualified them. Being aware of the importance of self-satisfaction and students' feelings, we have consulted their opinions about the method, which we show briefly to complete this paper. We end with some conclusions and suggestions for improvements in future applications.

\section{Material and methods}

As we said above, Microeconomics is characterized by an elevated conceptual component, often with a great level of abstraction, which is the basis to learn Economics [6, 7]. It also requires an analytical component, which serves as structure to these concepts, and the geometrical tools that allow seeing them. These three 
elements constitute the supports to teach the subject, and their combined use is very useful to achieve the target of transmission of the knowledge with solidity and fiability. But its diversity supposes some difficulties for teaching, because we must use simultaneously the mathematical analysis and the graphic representations as support to the concepts, and for evaluation and qualification. A proper assessment should consider these differential aspects and allow the teacher see the level acquired by each student on each of them.

Because of this, our proposal consists of three parts: 1 . The face to face evaluation, to assess the capability of reasoning, that must be demonstrated by developing analytical expressions and solving problems related to mathematical microeconomic matters, and also the ability to appreciate some situations and their reflection in the corresponding graphs. 2. The on-line evaluation, which focuses on very specific conceptual issues, which are the main features of the discipline that we deal with. We will refer to the development, evaluation and qualification of a multiple choice test in a virtual environment and its application to a subject of Microeconomics, since it is a discipline characterized by a notable component of detail and abstraction. But, for the same reason, we think the procedure would be equally valid for Macroeconomics. 3. Finally, we must choose the weighing of the two parts to get the final grade.

\subsection{Design Test}

In the actual structure of teaching, we distinguish the expositive sessions (theoretical or magistral classes) from interactive sessions (practical or cases resolution classes, with the direct participation of pupils, that requires a major implication). To apply ELFF methodology, for each unit of the program that we develop in the expositive sessions, we elaborate a set of "n" questions of multiple choice, with four alternative answers, but only one correct. These questions, which correspond with worked concepts in the unit, once introduced in the section "Issues" of the Moodle platform, constitute the material for the design of the interactive test. The number " $\mathrm{n}$ " of proposed questions is at the discretion of teachers. Moreover, we must take into account that on being answered in a virtual environment, outside the classroom, the students will have access to the information that they consider appropriate and they will be able to communicate with each other.

\subsection{Design of the evaluation}

Considering all the foregoing, we decided to prepare, for each unit of the subject and for each pupil, a test of 10 questions randomly chosen among the 40 of the database. Thus, we can reach nearly 850 million of different questionnaires (specifically $847,660,528)$. This is a fundamental matter, because it grants, almost one hundred per cent, that each student must answer a different test, since the probability that two of them are identical is very small. Additionally, using the option of Moodle platform, we shuffle the questions and the answers, which will be in a distinct position in each questionnaire. When we introduce the questions in the virtual platform we assign a score to each, and the responses are measured in percentage terms: the value of the right answer is the 100 per cent, and wrong answers can be valued, also in percentage terms, with negative scores, being possible penalize more 
some answers than others. In our case, all questions were scored with 1 point, so that the right answer sums 1 point to the qualification, and we have selected a uniform penalty of 50 per cent for each wrong answer, which subtracts 0.5 points.

Moreover, these questions were grouped in the database according to clusters, i.e., for each test, we divided the matters under consideration in 10 blocks with different contents, and we have developed 4 questions for each one of the contents. These questions were what have built the database. Thus, our database consisted of 40 questions, related with 10 different aspects of the subject under discussion, and each of these aspects was developed in 4 questions, which have been formulated with similar level of difficulty. However, the difficulty level can vary between blocks.

Subsequently, we prepared the Moodle Platform program to include in each test 1 question from each one of the 10 clusters of 4 questions, at random. Thus, the resulting questionnaire was composed of 10 questions, each from a different thematic area. This ensures that each student will be evaluated with a different exam but balanced in content, taking in account in each and every one of the tests all the aspects of the theme. In our opinion, this system combines the basic criteria of efficiency (all tests are covering all the main matters) and equity (all tests are balanced in content and level of difficulty for all students).

\subsection{Online evaluation}

Once set up the questionnaire, we design how to run it. First, we agree with pupils a date and a time environment (two hours) for conducting the test. Although it is probably better to make the proof in a classroom where each pupil has a computer with internet access, we choose facilitate solving in the environment that students preferred, being aware of that this means that they can consult references and/or have assistance to answer. We try to prevent copies or cooperative resolution of the exam by setting only one attempt for choose the right answer and by limiting the time to do the questionnaire to a maximum of 20 minutes after opened.

Summarizing: students will have to answer a test of 10 multiple choice questions, 1 question from each one of the 10 clusters of 4 questions, selected at random. In different questionnaires it could be repeated any question but, if so, it will not be located in the same position, nor has ordered the responses in the same way. Each question has only one correct answer which is worth 1 point, and 3 incorrect, that subtract 0.5 points. The test can be answered from any location with internet access, but in the day "d", between the hours "h" and "h+2", and there is only one attempt to answer every question correctly. By pressing the key to start, the countdown begins from 20 minutes to answer, and even if the test is not complete, when the time finish, the program automatically will close and will send the questionnaire for evaluation.

Given that students can communicate and transmit information about the test content, they have an aversion to be the firsts to start the process, since the firsts are in a situation of disadvantage: they lack the data to which their peers can access by answering the questionnaire later, because they could collect information from those who have done it before. Although this matter is minimized by the structure of 
blocks of the test, that we have explained above, we have established an additional mechanism to minimize the advantages of "moving into second", by hiding the feedback about the correct answers and scores until the process was fully completed and the questionnaire was closed for answering.

Therefore, students received no feedback until all of them had completed the all of test. That is, each student solved its questionnaire and sent it to the Moodle platform for evaluation, but he did not know if he had failed or succeeded nor the grade earned until the process was closed. This data were sent to pupils only when the time available to answer was finished. Thus, the information transmitted between the students, if any, would be in any case incomplete, as they would not know the correct answers. This, plus the limited availability of time for the resolution of the test, makes we consider high the reliability of individual responses.

\subsection{Qualification procedure}

Qualification is obtained automatically, by means of the parameters specified at the time of preparation of the test. The system, as we have said, allows evaluating in different ways each of the questions, and also to discriminate in assessment of the penalties, which substantially increases the range of possibilities. Randomness in questions (i.e., that a question will be in an exam, but not in another), together with a penalty different for different mistakes may cause some discomfort among students. Although in this experience we have not used this option, we would like to point out that higher penalties would be linked to clearer errors, then, the likelihood to give those answers would be minor, precisely because they are important mistakes, and we think that this would compensate the major penalty. However, this opens a debate that can originate many stimulating ideas. As regards the randomness of the questions, we attempted that all were of a similar difficulty.

There are three basic aspects that confer a special status to this phase of qualification, because they usually cause some suspicions about the procedure proposed:

1. The teacher needs to know with certainty that is the student being evaluated who solve the test.

2. The test must be made individually, without collaboration from people outside and without using supporting material such as bibliography, notes or any other type of resources. However, the possibility of access to these materials or the cooperative association may be considered as a disadvantage or as an advantage, since it could serve to train pupils in consultation of bibliography or encourage teamwork. The valuation in either direction will depend on the objective pursued and the level or difficulty of the questions.

3. Students must make a similar test, with a minimum level of homogeneity, to avoid unfair situations by differences in degree of difficulty. 
Other aspects, also important, are the need to access to the platform, the possible differences among students in the ability with informatics' tools or the lack of habit of making tests in loneliness. All these issues are still to be resolved, although, in our opinion, they are acceptably minimized in this proposal, because all our pupils declared to have internet access and to feel able to make correctly the proof. Although the questionnaire for each student has a similar level of difficulty than the corresponding to another, it is, almost certainly, different. Pupils can answer each question only once and they have a limited time approximately two minutes to answering it, to make difficult the copy or the cooperative resolution. The most difficult problem is to determine who makes the test. Although students enter to the platform with their personal password, someone else could do it instead. After this experience, seeing that the results of classroom exams are consistent with those obtained in conducting questionnaires, we have not detected that such situation had happened, although one can not ensure. In any case, in future academic years, probably we will opt for the resolution of the tests in a net classroom. Moreover, this procedure has many positive aspects, both for students and for teachers. Among them we point out:

1. It has all the advantages of the traditional test exams, that avoid bias in ratings due to the subjectivity of the qualifier.

2. It provides a wide range of possibilities for qualifying because it allows a different evaluation of each question and a different penalty for each wrong answer.

3. Students can work in the environment they consider appropriate.

4. It could, if appropriate, be used to assess group work.

5. It helps to improve the acquisition of concepts, because the platform allows including comments on the incorrect answers that students receive with your score, so that everyone can recognize and correct their mistakes.

\subsection{Mastering microeconomics via test}

The long lectures are no longer the main focus of teachers, as the techniques pupilcentered study are imposed more and more forcefully. However, many authors claim that greater on-line interaction does not lead to significantly higher performance. Despite this, students who failed in their courses tended to interact less frequently [10]. This could mean that interaction is a significant component of successful of learning [11].

Interaction is an intrinsic feature of the method of learning that we propose, as the tests on-line are part of the evaluating procedure. And this seems to improve, at least, the qualifications that our pupils get. In this section we analyze the results. 


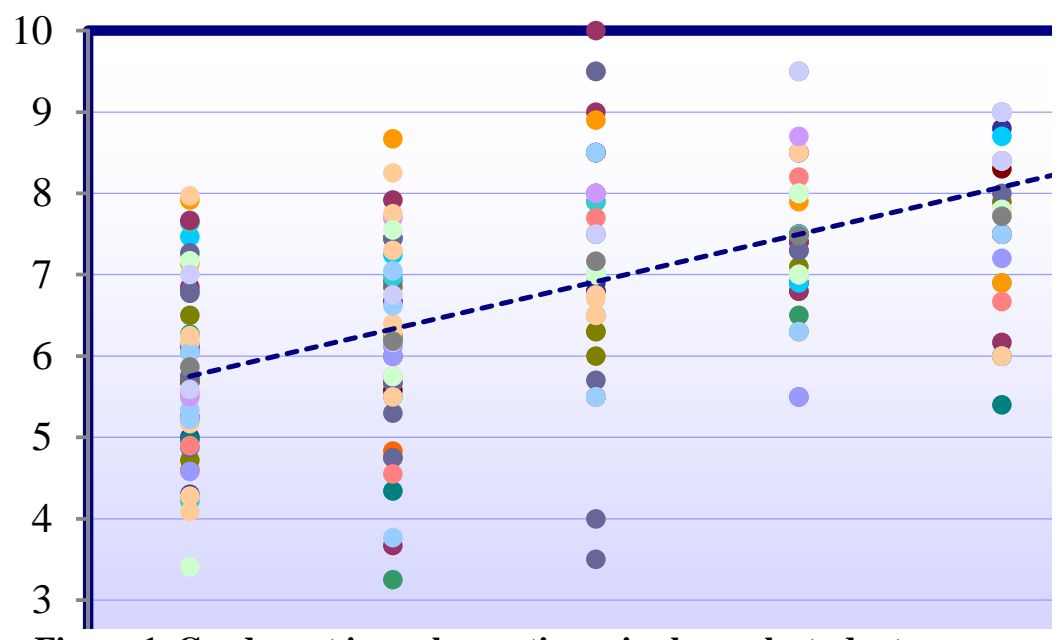

Figure 1. Grades get in each questionnaire by each student

Figure 1 display the scores reached for students from the first test performed (Q1) to the last (Q7). The points in each color represent the corresponding scores to a pupil (OY exe). As they are 46 pupils, it is not easy analyze their individual evolution, but the graphic shows a clear upward trend in the performance according to the number of questionnaires completed. We think that this procedure increases the relationship of each student with the group because after each test, he makes comments, consults and discusses its results with peers, to clarify where he has made mistakes and correct them. And usually, their fellows are willing to collaborate by explaining anything if needed.

The group, meanwhile, also improve, because by trying to resolve the doubts of some of its members, usually consults references, gives examples and clarifies its ideas. The students become aware of that, the more and better are the references consulted and the less are the questions that remain unresolved, they have a greater chance of success. This realization forces the student to join the group, and thereby adds its individual learning to the knowledge of the collective, that increases significantly, with a minimal effort. On the other hand, each questionnaire is different for each student. This strengthens the student's responsibility in their work. He will be the ultimate decision maker when it comes to answering the test. Thus, we combine in one instrument, the individual responsibility and the group cooperation.

As we say, several are the positive consequences that we expect of this experience. First, and the most important, to improve the knowledge and the understanding of the subject. Second, to increase of individual motivation and to promote the union of the group, by generating an attitude of cooperation that leads to a global increase in performance. 


\begin{tabular}{cccccccc}
\hline & Q1 & Q2 & Q3 & Q4 & Q5 & Q6 & Q7 \\
\hline P1 & 3.70 & 8.76 & 8.74 & 7.67 & 9.71 & 10.00 & 10.00 \\
P2 & 5.88 & 2.82 & 5.45 & 9.07 & 9.54 & 6.96 & 10.00 \\
P3 & 5.85 & 6.28 & 8.98 & 6.52 & 9.54 & 9.67 & 9.35 \\
P4 & 5.73 & 7.38 & 6.04 & 6.50 & 8.02 & 7.26 & 9.87 \\
P5 & 5.68 & 5.63 & 7.38 & 8.11 & 8.57 & 9.00 & 9.67 \\
P6 & 6.68 & 5.27 & 7.17 & 7.65 & 8.37 & $8 . .11$ & 9.54 \\
P7 & 5.46 & 5.51 & 7.74 & 7.20 & 7.45 & 8.57 & 9.28 \\
P8 & 7.01 & 7.35 & 7.48 & 5.41 & 6.87 & 8.13 & 8.13 \\
P9 & 6.54 & 6.00 & 6.65 & 8.22 & 9.15 & 8.09 & 10.00 \\
P10 & 6.11 & 6.73 & 6.74 & 8.43 & 9.87 & 9.59 & 9.87 \\
\hline Average & $\mathbf{5 . 8 6}$ & $\mathbf{6 . 1 7}$ & $\mathbf{7 . 2 4}$ & $\mathbf{7 . 4 8}$ & $\mathbf{8 . 7 1}$ & $\mathbf{8 . 5 4}$ & $\mathbf{9 . 5 7}$ \\
\hline
\end{tabular}

Table 1. Average grade got by students in each question of each questionnaire

We can analyze if our expectations are realistic by using the numeric grades got by students along the time. These results may be observed in Table 1 , that shows the average score of pupils in the question "i" of the test " $\mathrm{j}$ ", being this result in row "Pi" and column "Qj". It is noted that, although the degree of difficulty of Microeconomics increases as the course progresses, the average grade in the on-line questionnaires is higher in the last tests than in the firsts ${ }^{1}$. Also it is worth noting that the content on this table allow us to detect what questions have been more difficult and easier for students. This is very important, because if we found the most complex concepts to understand, we can try to explain them better, to avoid this problem in the future.

\section{Results}

Facing to the rating scheme that we have been using so far, in which the maximum score of 10 points which qualify the subject were assigned to the exams in the classroom, in this proposal, to this kind of proofs we assign only a maximum of 7 points. Tests on-line were valued with a maximum score of 3 points, divided between 7 tests, each one related to one of the themes of the subject.

To analyze how this change affects the results, in terms of qualifications, although we should take into account that not all promotions have the same capabilities, we could compare the results obtained by the students of this subject in this course with those of previous. But that comparison is not possible, since the subject Microeconomics: Markets and Competition in the European Union was taught for the first time in this academic year.

\footnotetext{
${ }^{1}$ The only exception is shown in the questionnaire 6 , where we have a small decrease in the average test result. This could be due to that this test corresponds with the theme of oligopoly, an especially complex issue in this subject.
} 
Microeconomics: Markets and Competition in the EU - Academic Year 2010-11

\begin{tabular}{lcccr}
\multicolumn{5}{c}{ Statistics by subject } \\
\hline Subject & \multicolumn{1}{c}{ DB } & DB\&L \\
Overcome & Students & Percent & Students & Percent \\
Unmastered & 61 & 28,6 & 36 & 78,3 \\
Not submitted & 123 & 57,7 & 10 & 21,7 \\
& 29 & 13,6 & 0 & 0,0 \\
\hline & \multicolumn{2}{c}{ Statistics by degree } & DB\&L \\
\hline Degree & \multicolumn{7}{c}{ DB } & Students & Percent \\
Not submitted & Students & Percent & 0 & 0,0 \\
Exceeded & 29 & 13,6 & 10 & 21,7 \\
Passed (C/D) & 123 & 57,7 & 22 & 47,8 \\
C/B & 43 & 20,19 & 12 & 26,1 \\
A/A & 15 & 7,0 & 2 & 4,3 \\
\hline
\end{tabular}

Table 2. Microeconomics: Statistics by subject and by degree

Therefore, to have at least some indicator that provides information about the running of the method, we proceeded to compare the results obtained in the same subject in the degrees in Business Administration and Management (DB), in which we use the traditional methodology, and in the double degree in Law and in Business Administration and Management (DB\&L), in which we use the ELFF mixed methodology.

In this comparison we must take into account that the subject is identical in both grades, it has the same program, and it was taught by the same teachers. But students of DB\&L have traditionally achieved better grades than the ones of DB. The average approved in the four previous years in a similar subject to this one that was assessed with traditional methods, was in DB\&L 18.5 percentage points higher than in DB.

In Table 2 we can note, first, that in the DB, about 14 percent of enrolled students did not participate in assessment exams. By contrast, in the DB\&L, the proofs were made by all and each one of enrolled students. This is a very surprising and unusual result. The ELFF mixed methodology seems to be highly motivating of students' participation.

Moreover, as it can be seen, the success rate does not reach the 29 per cent among DB students, while among DB\&L students it exceeds the 78 per cent, i.e., in front of a average difference in previous academic years of about 18.5 percentage points we have now almost 50. But not only have we recorded a significantly higher percentage of pupils passed. As observed in the statistics by degree, in the DB\&L approved double of students than in DB, but the percentage of pupils that got notable and outstanding was more than triple. The students do not only approve more, but they achieve higher scores. 


\subsection{Conceptual relating knowledge as a tool to improve understanding of microeconomics}

In our work we found that, by resolving on-line tests, scores of students are higher; i.e., the ELFF mixed methodology seems to improve the results. But we think also, it leads to a major consistency among the correct answers. That is, the scores in each item of each test are more similar to each other.

\begin{tabular}{llc}
\hline & Standard Deviation \\
\hline $\mathbf{Q 1}$ & 0.908 \\
$\mathbf{Q} 2$ & 1.588 \\
$\mathbf{Q 3}$ & 1.097 \\
$\mathbf{Q 4}$ & 1.088 \\
$\mathbf{Q 5}$ & 1.028 \\
$\mathbf{Q 6}$ & 1.023 \\
$\mathbf{Q 7}$ & 0.572 \\
\hline
\end{tabular}

Table 3. Standard deviation among grades by item on each questionnaire

Trying to test this idea, we took the average grades for all students in each question and then, we calculated the standard deviation between the ten questions that make up each questionnaire. The results are listed in the Table 3.

As we can see, the trend of these deviations is decreasing. With the only exception from the first to the second, we have found that, in each new test, the standard deviation was minor than in the previous. From the second questionnaire until the seventh, the trend is clearly downwards.

\subsection{Perceived satisfaction and effectiveness of e-learning}

As a final important matter, we considered the perceptions of students regarding the on-line learning system, to evaluate the perceived satisfaction, the e-learning effectiveness, the relation between spent time in e-learning and its influence on grades and the general perception about the e-learning.

We made some statements about it, and we have used a Likert scale, with scores from 1 to 7 ( 1 meant absolutely in disagreement and 7 absolutely in agree), according to which students must show their level of agreement or disagreement with each sentence. 


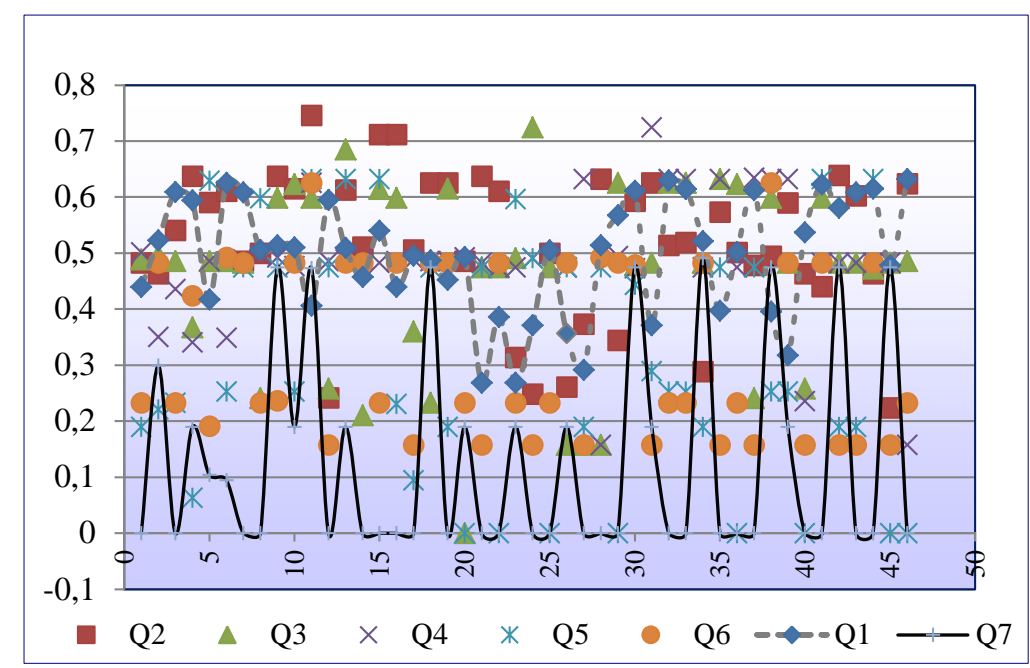

Figure 2 Standard deviation on grades for each student (average grade for each questionnaire)

Following Liaw [12], we questioned pupils about the sentences written in Tables 4 and 5: Table 4 is about perceived satisfaction and Table 5 is about e-learning effectiveness.

\section{Perceived satisfaction}

Min. Max. Average S.D.

1. I am satisfied with using e-learning as a learning assistant tool $\quad$\begin{tabular}{lllll}
\hline & 4 & 7 & 5.54 & 0.91
\end{tabular}

$\begin{array}{lllll}\text { 2. I am satisfied with using e-learning functions } & 3 & 7 & 5.18 & 0.85\end{array}$

3. I am satisfied with learning contents $\quad \begin{array}{llll}3 & 7 & 5.53 & 1.13\end{array}$

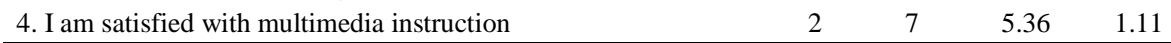

Table 4. Perceived Satisfaction

Source: Authors own, based on Liaw [12]

Min. Max. Average S.D.

5. I believe e-learning can assist learning efficiency

6. I believe e-learning can assist learning performance

$\begin{array}{llll}3 & 7 & 5.26 & 1.16\end{array}$

7. I believe e-learning can assist learning motivation

$\begin{array}{llll}1 & 7 & 5.00 & 1.38\end{array}$

\section{Table 5. E-learning effectiveness}

Source: Authors own, based on Liaw [12] 
We also asked students about self-perception about the influence of spending time on e-learning on their grades and about their own feelings, following CuadradoGarcia et al [13].

Results are reflected on Tables 6 and 7, respectively: Table 6 is about the relation between spending time in e-learning and its influence on grades and Table 7 is about the e-learning general perception.

\begin{tabular}{lcccc}
$\begin{array}{l}\text { Relation between spending time and e-learning: } \\
\text { Influence on grades }\end{array}$ & Min. & Max. & Average & S.D. \\
\hline $\begin{array}{l}\text { 8. 8. I think that required time will have a negative effect on my } \\
\text { social life and on other grades }\end{array}$ & 1 & 6 & 2.05 & 1.57 \\
$\begin{array}{l}\text { 9. I will receive a good score that will increase my grade point } \\
\text { average }\end{array}$ & 1 & 7 & 4.72 & 1.45 \\
\hline
\end{tabular}

Table 6. Self-perception about grades

Source: Authors own, based on Cuadrado-García et al [13]

\begin{tabular}{lcccc} 
E-learning general perception & Min. & Max. & Average & S.D. \\
\hline 10. I enjoy e-learning as an interesting subject & 1 & 6 & 4.03 & 1.20 \\
11. I found on-line communication a friendly experience & 3 & 7 & 5.13 & 1.00 \\
\hline
\end{tabular}

Table 7. Enjoying learning on-line

Source: Authors own, based on Cuadrado-García et al [13]

\section{Discussion}

The results analyzed show that the grades achieved by students when we apply the mixed method are higher than with the traditional evaluation. In our opinion, this is because of that the continuous evaluation through questionnaires forces students to prepare the subject as it is explained. So that, every concept is well established before we teach a new topic, and, therefore, it can be better assimilated.

About the conceptual relating knowledge as a way to improve understanding of Microeconomics, the decreasing trend of standard deviation of the average test qualifications, in our opinion, means that the score between the different items is becoming more homogeneous. Our explanation is that students are assimilating concepts in a more global mode, resulting in a greater affinity on successes or failures, when they solve the questionnaire. That is, the degree of understanding is more similar for all items of each questionnaire at the end of the course that at the beginning. The fact of the standard deviation follow the same trend for all the students reinforces our guess.

Related to the satisfaction perceived by students, the average of responses in all questions exceeds the value 5 , that is to say, their perception is positive or very positive, both with the tools, as with the contents. It is especially rewarding the 
positive assessment of question 3, since it refers to the contents. The database of questions, has been entirely elaborated by the team of microeconomics. This point is very important because it is precisely the link between face to face teaching and the e-learning, and is, therefore, the core of mixed methodology that we propose.

The majority of students also agree with the effectiveness of ICT as a means of learning, since, in any sentence, the average of valuations is above the mean. These results are encouraging, as indicate that students constitute a solid support to our method. They think that is a more efficient and motivating system than face teaching.

Related to students' feelings about the use of their time, they agree or strongly agree that they are not wasting their time using e-learning tools, and that they grades will not suffer a negative influence. Even more, they trust on their grade point average will improve with this experience.

Finally, the students showed their satisfaction with this e-learning experience and with the qualification system, because it leads to continuing study that results in an increase in their chances of overcoming and mastering the subject. In fact, by using on-line technologies, they expect to improve their average scores. Related to Microeconomics, these expectations have been met, as we have explained throughout this work.

\section{Conclusions}

In the course Microeconomics: Markets and Competition in the European Union, of the double degree in Law and in Business Administration and Management, the application of a mixed methodology for the evaluation and qualification, by combining traditional exams in the classroom with others in virtual environments, that encourage the participation and self-learning, showed very positive results in terms of involvement of students and in improvement in knowledge acquisition and, therefore, in obtained scores.

The multiple choice tests that we propose, although more costly in time of preparation than tests of broad and open-ended questions, are of automatical correcting, and they facilitate the rating, because they use a very accurate scale for assesment of knowledge and valuation of errors, which we can evaluate at different levels, depending on the estimate of its importance.

Further, it provides a very valuable information to improve teaching, because the platform used to implement them summarizes in detail the results, so we know what questions fail pupils, what is the percentage of errors in each, etc. , and we can detect which are the particularly complex concepts.Moreover, the tests also help students improve the acquisition of knowledge, because the platform allows to include feedback on incorrect answers, that students receive automatically with your score, so each one can know and correct their mistakes. Finally, students have 
shown their favorable attitude to the on-line educational resources, and, in general, they achieved better grades, as they expected to.

\section{Acknowledgements}

The authors wish to thank the valuable recommendations of reviewers and the helpful comments of José Manuel Sanchez Santos and Ramón Varela Santamaría.

\section{References}

[1] Duart, J. and Martínez, M. (2001). Evaluación de la calidad docente en entornos virtuales de aprendizaje. In:

http://reddigital.cnice.mec.es/6/Documentos/docs/articulo12_material.pdf

[2] Duart, J.M. and Sangrá, A. (2000). Aprender en la virtualidad. Barcelona: Gedisa, Edicions de la Universidad Oberta de Catalunya.

[3] UE (2000). Concebir la Educación del futuro: Promover la Innovación con las Nuevas Tecnologías. Bruselas: Informe de la Comisión al Consejo y al Parlamento Europeo.

[4] Baeten, M.; Kyndt, E.; Struyven, K. and Dochy, F. (2010). Using student-centred learning environments to stimulate deep approaches to learning: factors encouraging or discouraging their effectiveness. Educational Research Review, 5, 3, 243-260.

[5] Hartwell, L.M.(2010). Impact of software design on non-line text reconstruction. Computers \& Education, 38, 3, 370-378.

[6] Martín Caraballo, A.M. and Segovia González, M.M. (2010). Implantación de nuevas metodologías y técnicas de evaluación en la Facultad de Empresa. Revista de Formación e Innovación Educativa Universitaria, 3, 2, 57-68.

[7] Lopes dos Reis, F. and Martins, A.E. (2010). Virtual teaching in a society of learning. Revista de Formación e Innovación Educativa Universitaria, 2, 1, 1-7.

[8] Ning, H.K. and Downing, K. (2010). Connections between learning experience, study behaviour and academic performance: a longitudinal study. Educational Research, 52, 4, 457-468.

[9] Sangrá, A. (2001). La calidad en las experiencias virtuales de educación superior. Madrid: Virtual Educa. In:

http://www.uoc.edu/web/esp/art/uoc/0106024/sangra.html

[10] Davies, J. and Graff, M. (2005). Performance in e-learning: online participation and student grades. British Journal of Educational Technology, 36, 4, 657-663. 
[11] Su, B; Bonk, C.J,: Magjuka, R.J.; Liu, X. and Lee, S. (2005) The importance of interaction in web-based education: a program-level case study of online MBA courses. Journal of Interactive Online Learning, 4(1), 1-19.

[12] Liaw, S.S. (2009) Investigating students' perceived satisfaction, behavioral intention, and effectiveness of e-learning: A case study of the Blackboard system. Computers \& Education, 51, 864-873.

[13] Cuadrado-Garcia, M. Ruíz-Molina, M.E, Montoro-Pons, J.D. (2010) Innovation and Creativity in Education. Procedia - Social and Behavioral Sciences, 2, 2, 367371. 